\title{
Severe hypertriglyceridemia-induced pancreatitis in young female managed with plasmapharesis. A case report
}

\author{
Ahmed A Khalifa ${ }^{1}$, Sheref A Elseidy ${ }^{1 *}$ and Ahmed M Khalifa ${ }^{2}$ \\ ${ }^{1}$ Department of rheumatology, Ain shams university, Egypt \\ ${ }^{2}$ Department of forensic medicine and toxicology, Ain Shams University, Egypt
}

\begin{abstract}
Background: Hypertriglyceridemia (HTG) is reported to cause 1-4\% of acute pancreatitis (AP) episodes.Serum triglyceride (TG) levels above 1,000 mg/dl are usually considered necessary to ascribe causation for AP. The mechanism for HTGP is postulated to involve hydrolysis of TG by pancreatic lipase and release of free fatty acids that induce free radical damage. The reduction of triglyceride level to below $1000 \mathrm{mg} / \mathrm{dL}$ effectively prevents further episodes of pancreatitis. The mainstay of treatment for the hypertriglyceridemia associated with pancreatitis includes dietary restriction of fat and administration of lipid-lowering agents, Experiences with plasmapheresis are limited.
\end{abstract}

Case presentation: This case reports a young female, 22 years old female patient nonalcoholic, non-diabetic, non-obese with negative history for gall stones or significant drug use diagnosed with hypertriglyceridemic acute pancreatitis associated with acute kidney injury, and received one session of hemodialysis then plasmapharesis was initiated and she received 8 sessions with full dose of hypolipidemics, and responded only to plasmapharesis.

\section{Introduction}

Hypertriglyceridemia (HTG) is the third most common cause of acute pancreatitis (AP) episodes [1-3]. AP caused by hyperlipidemia is the same as in all types of pancreatitis. Exclusion of heavy alcohol consumption, gallstone disease and secondary causes as drugs and iatrogenic causes, A family history of lipid abnormalities should be identified. Current guidelines of management include full dose hypolipidemic mainly fibrates, minimization of dietary fat consumption, insulin and/or heparin, administration of plasmapheresis and/or lipid pheresis have be found to be the most useful in reduction of TG levels, improving of clinical signs and symptoms during the active phase of pancreatitis also effectively preventing further episodes of pancreatitis $[4,5]$.

In this case report a female patient with positive family history for hyperlipedemia, no past significant history of diabetes or history of alcoholism or gall stones or significant drug history, was diagnosed with hyperlipidemia induced pancreatitis and received one session of hemodialysis then plasmapharesis was initiated and she received 8 sessions with full dose of hypolipidemics. She responded only to plasmapharesis which reversed the acute attack and exponentially reduced her TGs levels, but recurrence occurred although multiple sessions of plasmapharesis were done.

\section{Case presentation}

Young 22-year-old female patient presented to our ER by epigastric pain radiating to the back, vomiting and fever.

$\mathrm{O} / \mathrm{E}$ : she was fully conscious, feverish, with epigastric tenderness.

Pelvi-abdomenal ultrasound showed bulky heterogeneous pancreas with surrounding rim of free peripancreatic fluid collection and was diagnosed with pancreatitis.
While withdrawing her blood for laboratory tests, her blood looked milky white.

Laboratory results showed: elevated kidney functions (creatinine $3.4 \mathrm{mg} / \mathrm{dL}$ ) and serum amylase $209 \mathrm{IU}$. She had hyperlipidemia, her TGs level was $(1335 \mathrm{mg} / \mathrm{dL})$ and serum cholesterol was $(750 \mathrm{mg} / \mathrm{dL})$. She did not improve on full dose of hypolipidemics, then developed acute kidney injury and her serum blood urea nitrogen was $72 \mathrm{mg} /$ $\mathrm{dL}$ and serum creatinine were $6.3 \mathrm{mg} / \mathrm{dL}$ and received one session of hemodialysis followed by 8 sessions of plasmapharesis with full dose of hypolipidemics. She responded only to plasmapharesis. Her TGs and cholesterols started to decrease and reached $545 \mathrm{mg} / \mathrm{dL}$ and $194 \mathrm{mg} /$ $\mathrm{dL}$ respectively and she clinically started to improve, and her serum amylase was $11 \mathrm{IU}$. Plasmapharesis was stopped. Unfortunately, she deteriorated again with more severe symptoms and re-elevation of TGs and cholesterol. computerized tomography abdomen revealed bulky heterogeneous pancreas with high density fluid collection and multiple air foci suggestive of necrotizing pancreatitis with moderate ascites and bilateral pleural effusion. the patient then had 2 attacks of generalized tonic clonic fits followed by deterioration of conscious level. She developed disseminated intravascular coagulopathy (DIC) and acute respiratory distress syndrome (ARDS) and unfortunately, she passed away.

Correspondence to: Sheref A Elseidy $\mathrm{MBBCH}$, department of rheumatology, faculty of medicine, Ain shams university, Abbassyia 11566, Cairo, Egypt, Tel: +2001001571545, Email: drsherif.elseidy@gmail.com

Key words: acute pancreatitis, hyperlipidemia, hypertriglyceridemia, plasmapheresis

Received: December 03, 2017; Accepted: December 27, 2017; Published: December 30, 2017 


\section{Discussion}

The association between hyperlipidemia and acute pancreatitis was first reported in 1865 by Speck, the relationship then has been thoroughly studied in numerous papers and reports. The mechanism behind which hyperlipedemia leads to pancreatitis is thought to be that serum chylomicrons or triglycerides are hydrolyzed by the pancreatic lipase to generate free fatty acids that leads to and produce pancreatic capillary inflammation and thrombosis within the pancreatic capillary bed leading to pancreatitis. Free fatty acids also either exerts a toxic effect on pancreatic acinar cells or damages the capillaries directly via free radical damage. Elevated concentrations of free fatty acids in the pancreatic capillaries causes capillary inflammation and thrombosis leading to ischemia, infarction and acidosis, also free fatty acids in this highly acidic environment activate pancreatic enzymes and thus initiating acute pancreatitis [6-8].

The two major signs of hyperlipidemic induced pancreatitis are high serum triglyceride level above $1,000 \mathrm{mg} / \mathrm{dL}$ and the appearance of chylomicron in the serum at the early stage of pancreatitis in a nonobese non diabetic nonalcoholic patient with no other secondary cause for pancreatitis

Current management guidelines include: hypolipidemic agents, fat restriction, heparin infusion, insulin and plasmapharesis. However, with heparin the effect on triglyceride reductions is transient and the patient experience reaccumulation of TGS with long term infusion, on the other hand insulin use in non-diabetics has no clear evidence $[9,10]$.

Patients with HTG-AP are more likely to develop more profound systemic inflammatory response syndrome and end organ damage than in other types of pancreatitis [8] making therapeutic plasma exchange most beneficial to reduce serum triglyceride levels, as it was proposed that its efficacy is superior especially when there is evidence of shock or end-organ failure due to systemic inflammatory response syndrome [5].

In our case report the patient had a positive family history of hyperlipedemia and presented with severe type $\mathrm{V}$ hyperlipedemia in the acute phase at first of $(1335 \mathrm{mg} / \mathrm{dL})$, management with a trial of hypolipidemics was unsatisfactory and only Plasma exchange lowered the lipid level and TGs with a value reaching $(934 \mathrm{mg} / \mathrm{dl})$ after the first session. It also improved abdominal pain, the clinical state of the patients, and signs and symptoms of the disease but even though eight sessions were sufficient to control active disease they did not prevent recurrence in this patient with a more severe picture and superadded ARDS and DIC [11].

\section{Conclusion}

Plasmapharesis is the best treatment modality to reverse the acute phase of hyperlipidemic induced pancreatitis. However, the role plasmapharesis administration to prevent recurrence of acute pancreatitis remains unclear and further research is indicated.

\section{Competing interests}

The authors declare that they have no competing interests

\section{Ethical considerations}

Ethical approval for this case report was obtained from the Ethics Review Committee of Ain Shams faculty of medicine, informed consent was obtained following a full explanation of the procedure from first degree relative.

\section{References}

1. Tsuang W, Navaneethan U, Ruiz L, Palascak J, Gelrud A (2009) Hypertriglyceridemic Pancreatitis: Presentation and Management. The American Journal of Gastroenterology pp: 984-991.

2. Yadav D, Pitchumoni C (2003) Issues in hyperlipedimic pancreatitis. $J$ Clin Gastroeneterol 36: 753-758.

3. Fortson MR, Freedman SN, Webster PD (1995) Clinical assessment of hyperlipidemic pancreatitis. Am J Gastroenterol 90: 2134-2139. [Crossref]

4. Lennertz A, Parhofer K, Samtleben W, Bosch T (1999) Therapeutic plasma exchange in patients with chylomicronemia syndrome. complicated by acute pancreatitis. Ther Apher 3: 227-233.

5. Click B, Ketchum A, Turner R The role of apheresis in hypertriglyceridemia-induced acute pancreatitis: a systematic review. Pancreatology 15: 313-320.

6. Havel RJ (1969) Pathogenesis, differentiation and management of hypertriglyceridemia Adv Intern Med 15: 117-154. [Crossref]

7. Valdivielso P, Ramírez-Bueno A, Ewald N (2014) Current knowledge of hypertriglyceridemic pancreatitis. Eur J Intern Med 25: 689-694.

8. Nawaz H, Koutroumpakis E, Easler J (2015) Elevated serum triglycerides are independently associated with persistent organ failure in acute pancreatitis. $\mathrm{Am} \mathrm{J}$ Gastroenterol 110: 1497-1503.

9. Näsström B, Olivecrona G, Olivecrona T (2001) Lipoprotein lipase during continuous heparin infusion: tissue stores become partially depleted. J Lab Clin Med 138: 206-213.

10. Zhang K, Cox K, Sellers Z (2017) Plasmapheresis for Hypertriglyceridemia-Induced Acute Pancreatitis in a Child: A Case Report and Brief Review of the Literature. Pancreas pp: 58-59.

11. Dominguez-Muñoz JE, Malfertheiner P, Ditschuneit HH, Blanco-Chavez J, Uhl W, et al. (1991) Hyperlipidemia in acute pancreatitis. Relationship with etiology, onset, and severity of the disease. Int J Pancreatol 10: 261-267. [Crossref]

Copyright: (C2017 Khalifa AA. This is an open-access article distributed under the terms of the Creative Commons Attribution License, which permits unrestricted use, distribution, and reproduction in any medium, provided the original author and source are credited. 